\title{
UJI AKTIVITAS ANTIRADIKAL BEBAS FRAKSI DIETIL ETER BERUWAS LAUT (Scaevola taccada (Gaertn.) Roxb.) MENGGUNAKAN DPPH
}

\author{
A. Amaliah Dahlia, Rachmat Kosman, Halija \\ Fakultas Farmasi Universitas Muslim Indonesia \\ Email : dahliaamalia@yahoo.co.id
}

\begin{abstract}
Radical scavenging activity of diethyl ether fraction from sea lettuce tree (Scaevola taccada (Gaertn.) Roxb.) using DPPH.The of research aims is determine the radical scavenging activity of sea lettuce tree based on the binding of free radical $\mathrm{DPPH}$. Was conducted the research on test radical scavenging activity of sea lettuce tree (Scaevola taccada (Gaertn.) Roxb.) and then compared with the radical scavenging activity Vitamin C. Five thousand grams of sea lettuce tree (Scaevola taccada (Gaertn.) Roxb.) extraced by maceration using ethanol. Dry ethanol extract was partitioned with solid-liquid partition, using diethyl ether and then tested for activity and was obtained radical scavenging $\mathrm{IC}_{50}$ value $27,06 \mu \mathrm{g} / \mathrm{mL}$.
\end{abstract}

Key Word : Radical Scavenging, Scaevola taccada, DPPH

\section{PENDAHULUAN}

Beruwas laut (Scaevola taccada (Gaertn.) Roxb.) ditemukan di pantaipantai tropis di Samudra Pasifik dan India. Karena tersebar di beberapa daerah, Beruwas laut juga memiliki nama lokal yang berbeda - beda. Di Hawaii disebut naupaka kahakai, hal ini merupakan pertimbangan karena tempat tumbuhnya banyak disepanjang garis pantai naupaka (Mosquin, 2008).

Beruwas laut (Scaevola taccada (Gaertn.) Roxb.) memiliki beberapa manfaat dalam pengobatan. $\mathrm{Di}$ Filipina, rebusan akar dipakai untuk mengobati penyakit beri-beri, infeksi siphilis dan disentri. Di Thailand, akar dan daunnya digunakan untuk pengobatan penyakit kulit. Daunnya juga dapat dikunyah untuk meredakan batuk serta malaria. Begitu pula di beberapa pulau di utara Nugini, daun digunakan untuk mengobati batuk atau flu (Wardini, 2011).

Di Pinrang Beruwas laut (Scaevola taccada (Gaertn.) Roxb.) secara empiris digunakan untuk pengobatan berbagai penyakit. Diantaranya digunakan dalam pengobatan penyakit hipertensi dan diabetes mellitus. Hipertensi dan diabetes mellitus merupakan penyakit degeneratif, dimana penyakit 
degeneratif salah satunya disebabkan oleh adanya radikal bebas yang berlebihan di dalam tubuh.

Suatu radikal bebas ialah atom atau gugus apa pun yang memiliki satu atau lebih elektron tak berpasangan. Ciri umum dari hampir semua radikal bebas ialah kereaktifan kimia yang tinggi yang dikaitkan dengan kecenderungan elektron untuk terdapat sebagai pasangan (Pine, 1988).

Antioksidan adalah senyawa yang memiliki struktur molekul yang dapat memberikan elektronnya dengan cuma-cuma kepada molekul radikal bebas tanpa terganggu sama sekali dan dapat memutuskan reaksi berantai dari radikal bebas. Antioksidan banyak kita temukan dalam makanan yang berasal dari tumbuh-tumbuhan (Yuliarti, 2008).

\section{METODE PENELITIAN}

\section{A. Tempat dan Waktu Penelitian}

Pelaksanaan penelitian ini pada bulan Januari 2012 sampai April 2012. Dilaksanakan di Laboratorium Fitokimia Fakultas Farmasi Universitas Muslim Indonesia.

\section{B. Populasi dan Sampel}

Sampel yang digunakan adalah Beruwas laut (Scaevola taccada (Gaertn.) Roxb.) yang di ambil dari Kabupaten Pinrang, Sulawesi Selatan.

\section{Bahan dan Alat}

Bahan-bahan

yang digunakan adalah Aquadest, Beruwas laut (Scaevola taccada (Gaertn.) Roxb.), Dietil eter, DPPH (1,1-Diphenyl-2-Picryl Hydrazil), Etanol (96\%) P, Etil asetat, Lempeng Silica gel $60 \mathrm{~F}_{254}$, Metanol absolut, n-Heksan, dan Vitamin C.

Alat-alat yang digunakan adalah Alat gelas, Botol penyemprot penampak bercak, Chamber (Camag), Kamera, Lampu UV 254 dan 366 nm, Mikropipet (Memmert), Neraca analitik (Sartorius), Penangas listrik, Pengaduk magnetik, Seperangkat alat maserasi, Seperangkat alat rotavapor (Ika® RV 10 basic), Spektrofotometer UV-Vis (Apel PD 302UV), dan Stirer.

\section{Prosedur Kerja}

\section{Penyiapan alat dan bahan}

Alat dan bahan disiapkan sesuai dengan kebutuhan penelitian yang akan dilaksanakan.

2. Pengambilan dan Pengolahan sampel

Sampel Beruwas laut (Scaevola taccada (Gaertn.) Roxb.) diambil di Kabupaten 
Pinrang. Sampel kemudian dibersihkan dari kotoran yang melekat dengan menggunakan air mengalir lalu dikeringkan dengan cara diangin-anginkan. Setelah kering sampel dipotong-potong kecil, kemudian diekstraksi dengan metode maserasi.

\section{Pembuatan sampel}

\section{a. Esktraksi dengan pelarut etanol}

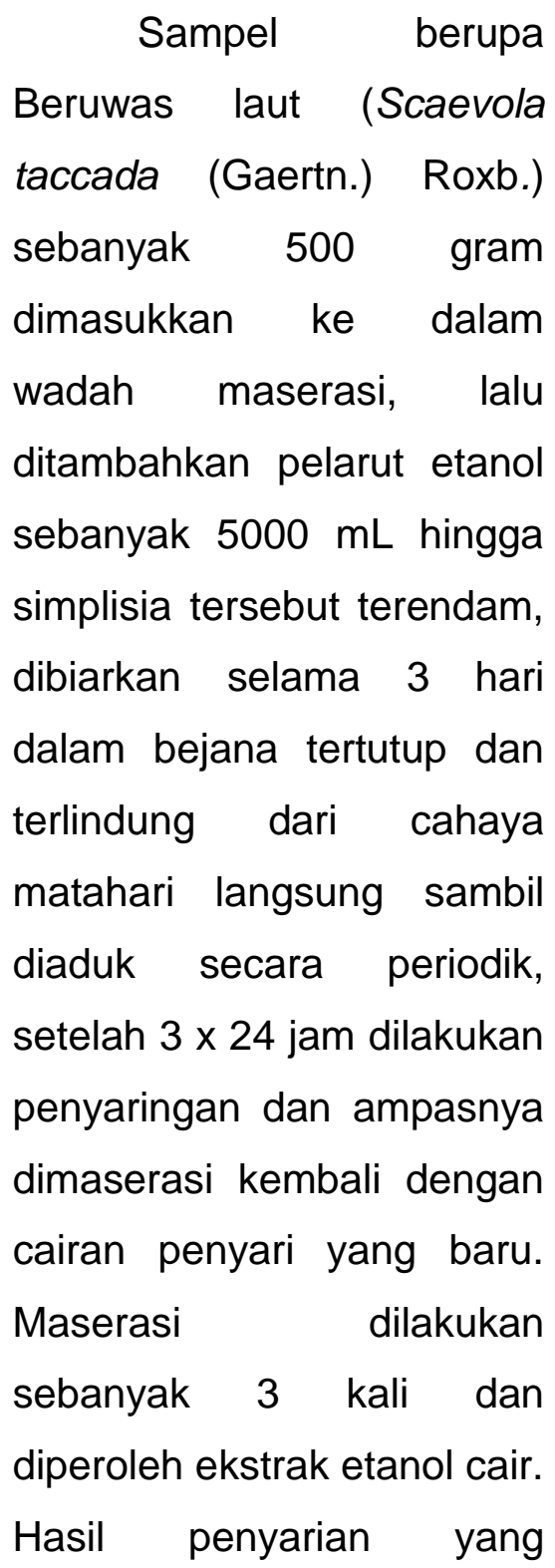

$\begin{array}{lr}\begin{array}{l}\text { diperoleh } \\ \text { diuapkan }\end{array} & \begin{array}{r}\text { kemudian } \\ \text { dengan }\end{array} \\ \text { menggunakan } & \text { rotavapor } \\ \text { sehingga akan } & \text { diperoleh } \\ \text { ekstrak kental. Ekstrak } & \text { kemudian } \\ \text { etanol kental keman } & \text { dikeringkan hingga diperoleh } \\ \text { ekstrak etanol kering. } & \\ \text { Diperoleh ekstrak etanol } & \\ \text { sebanyak 49,42 gram. }\end{array}$

b. Ekstraksi dengan Dietil eter

Ekstrak etanol kering yang diperoleh, diambil sebanyak 5 gram untuk diekstraksi dengan pelarut dietil eter dengan cara partisi padat cair yaitu ekstrak etanol kering tersebut dimasukkan kedalam labu Erlenmeyer $250 \mathrm{ml}$, lalu ditambahkan sekitar $50 \mathrm{ml}$ dietil eter. Batang pengaduk magnetik dimasukkan kedalam labu Erlenmeyer kemudian diletakkan diatas plat stirer. Stirer disambungkan dengan sumber arus listrik dan distel dengan kecepatan yang sesuai. Biarkan sampai pelarut jenuh, kemudian suspensi dikeluarkan dan dipisahkan antara padatan 


\begin{abstract}
dengan cairan. Bagian yang tidak larut dimasukkan kembali ke dalam Erlenmeyer dan ditambahkan $50 \mathrm{ml}$ dietil eter yang baru, lalu dilakukan seperti pada perlakuan pertama. Proses partisi padat cair ini dilakukan hingga pelarut dietil eter yang ditambahkan menjadi bening. Fraksi larut dietil eter dikumpulkan, pelarut diuapkan hingga diperoleh Fraksi dietil eter kering. Diperoleh fraksi dietil eter sebanyak 1,41 gram.
\end{abstract}

\section{Pembuatan larutan DPPH}

Larutan DPPH 0,4 mM dibuat dengan cara menimbang DPPH sebanyak 15,7 mg kemudian dilarutkan dengan $100 \mathrm{ml}$ metanol absolut dalam labu tentukur.

\section{Uji Aktivitas Antioksidan}

\section{a. Uji pendahuluan}

Fraksi Dietil eter Beruwas laut (Scaevola taccada (Gaertn.) Roxb.) ditotolkan pada lempeng KLT kemudian dielusi dengan menggunakan eluen n-Heksan : Etil Asetat (3:7). Lempeng $\mathrm{KLT}$ disemprot dengan menggunakan 1,1Diphenyl-2-Picryl Hydrazil (DPPH) dan dibiarkan mengering hingga terjadi perubahan dari warna ungu ke kuning.

\section{b. Pengukuran blangko}

Pengujian dilakukan dengan memipet $2,0 \mathrm{ml}$ $\mathrm{DPPH} \quad 0,4 \quad \mathrm{mM}$ dan dicukupkan volumenya dengan metanol absolut sampai $10 \mathrm{ml}$ dalam labu tentukur. Larutan ini kemudian dibiarkan selama 30 menit dan diukur absorbansinya pada panjang gelombang $517 \mathrm{~nm}$.

c. Pengukuran daya antioksidan Fraksi Dietil eter Beruwas laut (Scaevola taccada (Gaertn.) Roxb.)

Dibuat larutan stok 1000 ppm dengan cara menimbang Fraksi dietil eter Beruwas laut (Scaevola taccada (Gaertn.) Roxb.) sebanyak $50 \mathrm{mg}$ dan dilarutkan dengan metanol absolut sambil diaduk dan dihomogenkan lalu cukupkan volumenya hingga 
$50 \mathrm{ml}$. Selanjutnya dilakukan pengenceran :

1. Masing-masing larutan stok dipipet $0,2 \mathrm{ml}$ kemudian dicukupkan dengan metanol absolut sampai volume akhir 10 $\mathrm{ml}$ (20 ppm).

2. Masing-masing larutan stok dipipet $0,4 \mathrm{ml}$ kemudian dicukupkan dengan metanol absolut sampai volume akhir 10 $\mathrm{ml}$ (40 ppm).

3. Masing-masing larutan stok dipipet $0,6 \mathrm{ml}$ kemudian dicukupkan dengan metanol absolut sampai volume akhir 10 $\mathrm{ml}$ (60 ppm).

4. Masing-masing larutan stok dipipet $0,8 \mathrm{ml}$ kemudian dicukupkan dengan metanol absolut sampai volume akhir 10 $\mathrm{ml}$ (80 ppm).

5. Masing-masing larutan stok dipipet $1,0 \mathrm{ml}$ kemudian dicukupkan dengan metanol absolut sampai volume akhir 10 $\mathrm{ml}$ (100 ppm).

Pengujian dilakukan dengan memipet $100 \mu \mathrm{l}$ larutan sampel dari berbagai konsentrasi. Kemudian masing-masing ditambahkan 1,0 ml DPPH 0,4 mM dan dicukupkan volumenya dengan metanol absolut sampai $5,0 \mathrm{ml}$ dalam labu tentukur.

Campuran kemudian dihomogenkan dan dibiarkan pada suhu kamar selama 30 menit lalu serapannya diukur pada panjang gelombang $517 \mathrm{~nm}$. Prosedur diatas dilakukan secara triplo.

\section{d. Pengukuran daya} antioksidan sampel pembanding Vitamin C

Dibuat larutan stok 100 ppm dengan menimbang vitamin $\mathrm{C}$ setara $10 \mathrm{mg}$ kemudian dilarutkan dengan aquadest sambil diaduk dan dihomogenkan, volume akhir dicukupkan hingga $100 \mathrm{ml}$, kemudian dilakukan pengenceran :

1. Masing-masing larutan stok dipipet 0,2 ml kemudian dicukupkan dengan metanol absolut sampai volume akhir 10 $\mathrm{ml}$ (2 ppm). 
2. Masing-masing larutan stok dipipet $0,3 \mathrm{ml}$ kemudian dicukupkan dengan metanol absolut sampai volume akhir 10 $\mathrm{ml}$ (3 ppm).

3. Masing-masing larutan stok dipipet $0,4 \mathrm{ml}$ kemudian dicukupkan dengan metanol absolut sampai volume akhir 10 $\mathrm{ml}$ (4 ppm).

4. Masing-masing larutan stok dipipet $0,5 \mathrm{ml}$ kemudian dicukupkan dengan metanol absolut sampai volume akhir 10 $\mathrm{ml}$ (5 ppm).

Pengujian dilakukan dengan memipet $100 \mu \mathrm{l}$ larutan sampel dari berbagai konsentrasi. Kemudian masing-masing ditambahkan 1,0 $\mathrm{ml}$ DPPH 0,4 mM dan dicukupkan dengan metanol absolut sampai $5,0 \mathrm{ml}$ dalam labu tentukur. Campuran kemudian dihomogenkan dan dibiarkan pada suhu kamar selama 30 menit lalu serapannya diukur pada panjang gelombang $517 \mathrm{~nm}$.

\section{HASIL PENELITIAN}

Sampel Beruwas laut (Scaevola taccada (Gaertn.) Roxb.) sebanyak 500 gram diekstraksi secara maserasi menggunakan pelarut etanol sebanyak $15000 \mathrm{~mL}$, menghasilkan ekstrak etanol kental 49,42 gram. Selanjutnya ekstrak etanol kental sebanyak 5 gram dipartisi padat cair dengan menggunakan dietil eter sebanyak 150 $\mathrm{ml}$, sehingga dihasilkan fraksi dietil eter sebanyak 1,41 gram dan Fraksi dietil eter tersebut diuji aktivitas radikal bebas secara kualitatif dan kuantitatif.

Secara kuantitatif dilakukan dengan menggunakan DPPH dan kontrol positif (pembanding) vitamin $\mathrm{C}$, diperoleh nilai $\mathrm{IC}_{50}$ fraksi dietil eter Beruwas laut (Scaevola taccada (Gaertn.) Roxb.) sebesar 27,06 $\mu \mathrm{g} / \mathrm{mL}$ dan nilai $I_{50}$ vitamin $C$ sebesar 2,72 $\mu \mathrm{g} / \mathrm{mL}$ (Tabel 2). Sedangkan secara kualitatif sejumlah Fraksi dietil eter Beruwas laut (Scaevola taccada (Gaertn.) Roxb.) dilarutkan dengan menggunakan dietil eter hingga diperoleh kelarutan yang sesuai dan dilanjutkan dengan penotolan pada lempeng $K L T$, dielusi dengan eluen $n$ heksan : etil asetat (3:7), kemudian diamati pada penampak bercak UV $254 \mathrm{~nm}, 366 \mathrm{~nm}$, dan pengujian DPPH hasil kromotogram KLT. Uji aktivitas antioksidan dilakukan dengan menggunakan DPPH (1,1-diphenyl-2pycrilhidrazy), memberikan warna 
kuning pada lempeng dengan latar belakang warna ungu.

\section{PEMBAHASAN}

Penelitian ini menggunakan Beruwas laut (Scaevola taccada (Gaertn.) Roxb.) untuk memberikan data secara ilmiah dan metode ekstraksi yang digunakan adalah maserasi yang merupakan metode ekstraksi dingin. Metode ini tidak merusak komponen kimia Beruwas laut (Scaevola taccada (Gaertn.) Roxb.) karena tidak adanya pemanasan yang terjadi dalam proses ekstraksi. Ekstraksi yang dilakukan menggunakan cairan penyari etanol, dimana etanol merupakan pelarut polar yang bersifat tidak toksik, pelarut ini mempunyai keistimewaan tersendiri yaitu dapat menyari komponen polar maupun non polar yang berlebih.

Ekstrak etanol kental yang diperoleh selanjutnya dipartisi padat cair dengan menggunakan pelarut dietil eter. Penggunaan metode partisi padat cair dilakukan karena setelah dilakukan uji pendahuluan dengan cara melarutkan ekstrak etanol Beruwas laut (Scaevola taccada (Gaertn.) Roxb.) dengan air, diperoleh bahwa ekstrak etanol Beruwas laut (Scaevola taccada (Gaertn.) Roxb.) tidak larut dalam air. Hasil dari partisi padat cair yang telah dilakukan, lalu dilanjutkan dengan penguapan. Fraksi tersebut diuji aktivitas antiradikal bebas secara kualitatif dan kuantitatif dengan metode DPPH dan diperoleh nilai $\quad I_{50}$ sebesar $27,06 \mu \mathrm{g} / \mathrm{mL}$. Selain pengujian secara kuantitatif, pengujian aktivitas antiradikal bebas juga dilakukan secara kualitatif dengan KLT. Sampel ditotol pada lempeng KLT kemudian dielusi menggunakan cairan pengelusi $n$-heksan : etil asetat (3:7). Identifikasi kromatografi lapis tipis menggunakan cairan pengelusi eluen n-heksan : etil asetat (3:7), karena cairan pengelusi ini dapat mengelusi dengan penampakan warna dan jarak nodanya cukup jelas pada sampel yang ditotolkan pada profil Kromatografi Lapis Tipis (KLT). Setelah lempeng KLT dielusi kemudian disemprot dengan DPPH. Bercak yang memberikan perubahan warna menjadi kuning menunjukkan adanya aktivitas antiradikal bebas.

Aktivitas antioksidan merupakan kemampuan suatu senyawa atau ekstrak untuk menghambat reaksi oksidasi yang dapat dinyatakan dengan persen penghambatan. Metode yang digunakan dalam penelitian ini adalah metode DPPH. Metode DPPH digunakan karena sederhana, mudah pengerjaannya, cepat dan hanya memerlukan sedikit 
sampel serta cocok untuk semua sampel yang memiliki kandungan senyawa antioksidan. Senyawa antioksidan akan bereaksi dengan radikal DPPH melalui mekanisme donasi atom hidrogen dan menyebabkan terjadinya perubahan warna DPPH dari ungu ke kuning yang di ukur pada panjang gelombang 517 nm. Aktivitas antioksidan ditunjukkan dengan nilai $I C_{50}$. Nilai $I C_{50}$ merupakan nilai konsentrasi suatu zat antioksidan yang dapat menyebabkan 50\% DPPH kehilangan karakter radikal atau konsentrasi suatu zat antioksidan yang memberikan persen penghambatan $50 \%$. Zat yang mempunyai aktivitas antioksidan tinggi, akan mempunyai nilai $\mathrm{IC}_{50}$ yang rendah. Nilai analisis regresi ditunjukkan dari persen nilai aktivitas pengikatan radikal bebas DPPH. Nilai aktivitas antioksidan yang diperoleh akan dibandingkan terhadap antioksidan pembanding yaitu vitamin C (asam askorbat).

Menurut Ariyanto cit. Armala (2009), tingkat kekuatan antioksidan senyawa uji menggunakan metode DPPH dapat digolongkan menurut nilai $I C_{50}$.

\begin{tabular}{cc}
\hline Intensitas & Nilai $\boldsymbol{C}_{50}$ \\
\hline Sangat kuat & $<50 \mu \mathrm{g} / \mathrm{mL}$ \\
Kuat & $50-100 \mu \mathrm{g} / \mathrm{mL}$ \\
Sedang & $101-150 \mu \mathrm{g} / \mathrm{mL}$ \\
Lemah & $>150 \mu \mathrm{g} / \mathrm{mL}$ \\
\hline
\end{tabular}

Berdasarkan dari tabel diatas, maka tingkat kekuatan dari fraksi dietil eter Beruwas laut (Scaevola taccada (Gaertn.) Roxb.) termasuk sangat kuat karena nilai $\mathrm{IC}_{50}$ dari fraksi dietil eter Beruwas laut (Scaevola taccada (Gaertn.) Roxb.) adalah sebesar 27,06 $\mu \mathrm{g} / \mathrm{mL}(<50 \mu \mathrm{g} / \mathrm{mL})$. Nilai $I_{50}$ dari fraksi dietil eter Beruwas laut (Scaevola taccada (Gaertn.) Roxb.) dan vitamin $C$ dibandingkan sehingga diperoleh bahwa nilai $\mathrm{IC}_{50}$ dari vitamin $\mathrm{C}$ lebih kecil dari nilai $\mathrm{IC}_{50}$ fraksi dietil eter Beruwas laut (Scaevola taccada (Gaertn.) Roxb.). Jadi aktivitas antiradikal bebas dari vitamin $\mathrm{C}$ lebih baik daripada aktivitas antiradikal bebas fraksi dietil eter Beruwas laut (Scaevola taccada (Gaertn.) Roxb.).

\section{KESIMPULAN}

Berdasarkan hasil penelitian yang dilakukan dapat disimpulkan bahwa aktivitas antiradikal bebas fraksi dietil eter dari Beruwas laut (Scaevola taccada (Gaertn.) Roxb.) yaitu memiliki nilai $I_{50}$ sebesar 27,06 $\mu \mathrm{g} / \mathrm{mL}$.

\section{DAFTAR PUSTAKA}

Agoes, Goeswin. 2007. Teknologi Bahan Alam. Institut Teknologi Bandung, Bandung.

Anonim. 2007. Modul Kuliah Spektroskopi. Universitas Sanata Dharma, Yogyakarta. 
Anonim, 2009. Medicinal Plants in Papua New Guinea. World Health Organization, Philippines.

Ardiansyah, 2007. Antioksidan dan Peranannya Bagi Kesehatan, (Online), (http://ardiansyah.multiply.co $\mathrm{m} / 14$ ), diakses 15 Desember 2011).

Armala, M. M. 2009. Daya Antioksidan Fraksi Air Ekstrak Herba Kenikir (Cosmos caudatus H. B. K.) dan Profil KLT, Skripsi, 39. Fakultas Farmasi Universitas Islam Indonesia, Yogyakarta.

Chemical Book. 2008. (Online) (http://www.chemicalbook.co $\mathrm{m} /$ chemical productproperty EN CB8753 025.htm), diakses 12 April 2012.

Direktorat Jenderal Pengawasan Obat dan Makanan. 1979. Farmakope Indonesia Edisi III. Departemen Kesehatan RI, Jakarta.

Direktorat Jenderal Pengawasan Obat dan Makanan. 1986. Sediaan Galenik. Departemen Kesehatan RI, Jakarta.

Gandjar, I.G. 2007. Kimia Farmasi Analisis. Pustaka Pelajar, Yogyakarta.

Khopkar, S.M. 1990. Konsep Dasar Kimia Analitik. Universitas Indonesia Press, Jakarta.

LIPI. 2011. Hasil Identifikas i/ Determinasi Tumbuhan Beruwas Laut. Pusat Penelitian Biologi, Bogor.
Mosquin, Daniel. 2008. Scaevola taccada, $\quad$ (Online), (http://www.ntbg.org/plants/pla nt details.php?plantid=10272 Di akses 15 Desember 2011).

Maysatria, Yamato. 2011. Scaevola taccada, (Online), (http://muherda.blogspot.com/ 2011/02/scaevolataccada.html, Di akses 05 Januari 2012).

Mukarromah, Baitul. 2010. Dampak Radikal Bebas dan Antioksidan Terhadap Kesehatan Tubuh, (Online). (http://blog.unnes.ac.id/sitibait ul/archives/33. Diakses 03 Januari 2012).

National Tropical Botanical Garden. 2011. Scaevola taccada, (Online),(http://www.ntbg.org/ plants/plant details.php?planti $\mathrm{d}=10272$ Di akses 04 Januari 2012).

Ong, Hean Chooi. 2004. Tumbuhan liar: khasiat obatan \& kegunaan (Online), (http://www.scribd.com/doc/64 909444/Bio-Divers-It-As Diakses 15 Desember 2011).

Pine, Stanley H. 1988. Kimia Organik 2.Penerbit ITB, Bandung.

Sastrohamidjojo, Hardjono. 2007. Kromatografi. Liberty, Yogyakarta.

Stahl, Egon. 1985. Analisis Obat Secara Kromatografi dan Mikroskop. Institut Tekhnologi Bandung, Bandung. 
Uji Aktivitas Antiradikal Bebas Fraksi Dietil Eter Beruwas Laut Menggunakan DPPH

Stecher, Paul. 1973. The Merck Index Eight Edition, Merck \& Cl., INC. Rahway, N.J, USA.

Voight, Rudolf. 1995. Buku Pelajaran Teknologi Farmasi. Gadjah Mada University Press, Yogyakarta.

Wardini, T.H. 2011. Medicinal and poisonous plants, (Online) (http://www.proseanet.org/flor akita/browser.php?docsid=74 7, Di akses 04 Januari 2012).

Winarsi, Hery. 2007. Antioksidan Alami dan Radikal bebas. Kanisius, Yogyakarta.

Yuliarti, Nurheti, 2008. Racun di Sekitar Kita. Penerbit ANDI, Yogyakarta. 